\title{
Communication of bad news in the context of neonatal palliative care: experience of intensivist nurses
}

\author{
Comunicação de más notícias no contexto dos cuidados paliativos \\ neonatal: experiência de enfermeiros intensivistas \\ Comunicación de malas noticias en el contexto de los cuidados \\ paliativos neonatales: experiencia de enfermeras intensivistas
}

How to cite this article: Camilo BHN, Serafim TC, Salim NR, Andreato AMO, Roveri JR, Misko MD. Communication of bad news in the context of neonatal palliative care: experience of intensivist nurses. Rev Gaúcha Enferm. 2022;43:e20210040. doi: https://doi. org/10.1590/1983-1447.2022.20210040
- Universidade Federal de São Carlos (UFSCar), Departamento de Enfermagem. São Carlos, São Paulo, Brasil.

- Universidade Estadual de Campinas (UNICAMP), Faculdade de Enfermagem. Campinas, São Paulo, Brasil.

\section{Beatriz Helena Naddaf Camilo \\ Taynnara Caroline Serafima \\ Natália Rejane Salima \\ Álida Maria de Oliveira Andreato ${ }^{\mathrm{b}}$ Júlia Rudzinski Roverib Maira Deguer Misko ${ }^{b}$}

\section{ABSTRACT}

Objectives: To know the experiences of nurses in neonatal intensive care units in the face of the process of communicating bad news to the family of newborns in palliative care.

Methods: Study with a descriptive qualitative approach, in which 17 professionals participated. Data were collected through a semistructured interview script, from December/2018 to February/2019, and submitted to content analysis.

Results: Four theoretical categories emerged, with 11 subcategories inserted: meanings attributed to bad news; nursing as a support for the family; difficulties in dealing with the process of communicating bad news; nursing and involvement with the family's suffering. Final considerations: The challenges to deal with the situation are related to lack of preparation, impotence, and subjectivities. The results broaden knowledge on the subject and enable the improvement of nursing care in this context.

Keywords: Palliative care. Communication. Nurses. Infant, newborn. Intensive care units, neonatal.

\section{RESUMO}

Objetivos: Conhecer as experiências de atuação de enfermeiros em Unidades de terapia intensiva neonatal diante do processo de comunicação de más notícias à família de recém-nascidos em cuidados paliativos.

Métodos: Estudo de abordagem qualitativa descritiva, do qual participaram 17 profissionais. Os dados foram coletados através de um roteiro de entrevista semiestruturado, no período de dezembro/2018 a fevereiro/2019 e submetidos à análise de conteúdo.

Resultados: Emergiram quatro categorias teóricas, com 11 subcategorias inseridas: significados atribuídos à má notícia; a enfermagem como suporte à família; dificuldades para lidar com o processo de comunicação de más notícias; a enfermagem e 0 envolvimento com o sofrimento da família.

Considerações finais: Os desafios para lidar com a situação mostram estar relacionados à falta de preparo, impotência e subjetividades. Os resultados ampliam 0 conhecimento sobre a temática e possibilitam 0 aprimoramento da assistência de enfermagem nesse contexto.

Palavras-chave: Cuidados paliativos. Comunicação. Enfermeiras e enfermeiros. Recém-nascido. Unidades de terapia intensiva neonatal.

\section{RESUMEN}

Objetivos: Conocer las experiencias de los enfermeros de las unidades de cuidados intensivos neonatales ante el proceso de comunicación de malas noticias a la familia del recién nacido en cuidados paliativos.

Métodos: Estudio con enfoque descriptivo cualitativo, en el que participaron 17 profesionales. Los datos fueron recolectados a través de un guía de entrevista semiestructurado, desde diciembre / 2018 hasta febrero / 2019, y sometidos a análisis de contenido.

Resultados: Surgieron cuatro categorías teóricas, con 11 subcategorías insertadas: significados atribuidos a malas noticias; la enfermería como apoyo a la familia; dificultades para lidiar con el proceso de comunicar malas noticias; la enfermería y compromiso con el sufrimiento de la familia.

Consideraciones finales: Los desafíos para enfrentar la situación están relacionados con la falta de preparación, la impotencia y las subjetividades. Los resultados amplían el conocimiento sobre el tema y posibilitan la mejora de los cuidados de enfermería en este contexto.

Palabras clave: Cuidados paliativos. Comunicación. Enfermeras y enfermeros. Recién nacido. Unidades de cuidado intensivo neonatal. 


\section{口INTRODUCTION}

At the advent of neonatal medicine, the alternatives of care available for newborns (NB) who were premature or with life-limiting conditions were scarce. Within the context of the development of health sciences and, consequently, the expansion of resources and new technologies, there was an improvement in the care offered and the increase of the survival rates of this group of patients ${ }^{(1)}$.

With the advance of treatments, the neonatal mortality rate, in the year 2019, was $1.8 \%$, which corresponded to one death among 476 newborns before one month of life. From this index, $90 \%$ of them occur after complex decisions on treatments, which generates concern and worry about the way these decisions are being made and from which perspective they are based on ${ }^{(2)}$.

Despite the range of technological devices and the transition from the epidemiological profile that contributed to a significant reduction of neonatal mortality rates, there is a group of patients who will not reach a cure and then, will benefit from the philosophy and practice of palliative care. In neonatology field, the theme is gaining importance due to the high rates of prematurity, syndromes incompatible with life and the occurrence of congenital abnormalities ${ }^{(1,3)}$.

According to $\mathrm{WHO}$, palliative care is defined as prevention and relief of the suffering of patients and their families who go through complications inherent to life-threatening diseases. These complications include physical, psychological, social and spiritual suffering. In the neonatology field, a wide range of conditions can benefit from the palliative care: progressive and degenerative diseases such as spinal muscular atrophy, myelomeningocele, encephalopathies, chromosomal alterations (such as chromosomal trisomy 13-Patau's syndrome and 18-Edwards' syndrome), neonatal anoxia and prematurity are some of the conditions eligible for this philosophy. Thus, palliative care should be integrated into all levels of health care and with curative and life-sustaining treatments. Clear plans should be put into practice, to ensure that they continue without interruption or biases ${ }^{(3)}$.

Palliative care is described as holistic, dynamic, and complete care and must be extended during pregnancy, birth and mourning, prioritizing the respect and dignity of the patient and family. In the initial phase, palliative care can be allied to curative care and when the cure is not the care objective and the prognosis is critical, it is more evident ${ }^{(2,4)}$.

One of the most important pillars of palliative care is the communication. Most times, the philosophy is permeated circumstantially by the communication involving bad news. It is defined as bad news the information that can negatively affect the perception of an individual and his/ her family about the future or prognosis. The way how the news is given directly influences the way of looking and facing the problem ${ }^{(5)}$.

Literature points out for the need of support and information for patients beyond the moment of communication of bad news, and the nurse plays an important role in this context; they believe that their main function given the context is to offer support to the patient and their family members and to provide spaces of opportunities, in which people can speak openly(6).

The situation of communicating bad news becomes even more delicate when that patient is a newborn. Dealing with the inversion of the course of life, that is, with illness and the possibility of death in the first hours or days after birth negatively affects those involved. The family is shaken by this process, insistently seeking reasons and meanings for such an event, questioning the fragility of this life ${ }^{(7)}$.

The end of life process of a newborn in a neonatal intensive care unit (ICU) is something that affects many professionals in the health team. This is due to the fact that accepting the event of a baby's death is something difficult, as it goes against the natural order of life, of being born, growing up and dying. Monitoring the process of death and mourning in neonatology is a great challenge for nurses, given that the feeling that emerges during this moment is one of failure in their role in promoting and recovering health. In this context, nursing plays a preponderant and essential role for the baby's family that is following the process and experiencing negative feelings about the situation ${ }^{(8)}$.

The implementation of palliative care in the context of neonatal intensive care units is still little discussed and stigmatized. A study conducted with the objective of knowing the experiences and practices of nursing care in relation to the care offered to newborns and their families in the end of life situation in a neonatal ICU, showed that there is a lack of interprofessional discussion about practices, lack of implementation of a care plan for babies with critical prognoses incompatible with life and lack of communication involving decision-making, which is centered on the medical team, thus making scarce the participation of other team professionals in the process ${ }^{(6)}$.

Talking about the newborn's death to the family configures as a great challenge. Thus, the lack of preparation to deal with these situations makes health professionals establish a fragile communication, without creating bonds and the possibility of supporting parents in the painful process of communication and preparation for the process of dying and mourning $(9,10)$. 
It is strictly necessary for the nursing team to be present alongside the patient and their family, being this interaction with family members enables the offer of tranquility, support, comfort, empathy and welcoming and it is something that is directly related to how this news will be received and processed ${ }^{(2,3,4)}$.

Thus, the set of evidence points out to the relevance of the theme in question for the nursing field, neonatology and palliative care, as well as the gap in the area of research that addresses the relationship between the neonatologist nurse and the communication of bad news involving a newborn in palliative care, since that during the literature review, there is a scarcity of studies that address the experience of neonatologist nurses in the process of communicating bad news.

In view of the above, the present study had the following main question: how have nurses working in neonatal intensive care units dealt with the communication of bad news to the family of newborns in palliative care? Thus, the objective of the study was to know the experiences of nurses working in neonatal ICU in relation to the process of communicating bad news to the family of the newborn in palliative care.

\section{METHOD}

Study with a qualitative approach that favors the investigation of phenomena from the perspective of the person itself, in their reality and their context, analyzing and interpreting descriptive data based on written or spoken language or by observing the phenomena under study ${ }^{(11)}$.

The study was developed with nurses from three hospital units, of medium and high complexity, which had neonatal ICU and attended to babies in palliative care and their families, one of them located in the city of São Paulo and the other two in the interior of the state of São Paulo, cities of origin of the researchers. One institution was private and the others public and educational.

To capture the nurses in the study, it was used the Snow ball sampling technique ${ }^{(12)}$, known in Brazil as "snowball sampling", "snowball" or even as "informant chain". In it, the first interviewees indicate the next ones, and these, in turn, indicate others, and so on, until the proposed objective is reached ${ }^{(13)}$. For this purpose, the selection of research participants respected the following inclusion criteria: that the nurse was working in the neonatal ICU and with experience related to the provision of direct care to the newborn in palliative care and their family during and after the process of communicating bad news. Nurses who were away from their care functions or on vacation were excluded, considering the importance of experience in the scenario of communicating bad news.

The first participant was chosen randomly, being invited for respecting the research inclusion criteria. She was a member of a research group in which one of the researchers also participated and the invitation was made in person and formalized by sending an e-mail to forward the Free and Informed Consent Form (FICF). The subsequent interview was conducted after the indication of the first participant, and so on. The other invitations were made via e-mail or telephone contact, depending on what had been made available as a contact mechanism by the previous participant. The data collection period occurred between December 2018 and February 2019.

Thus, 17 nurses who worked directly in the health care of newborns hospitalized in the Neonatal ICU participated in the study. It is noteworthy that no nurse refused the invitation to participate in the study.

After the expression of interest, a convenient place and time for the interviewee was scheduled for data collection. Before starting the interview, the participant was asked to read and, agreeing, sign the FICF. It is noteworthy that this was printed in duplicate, both duly signed and delivered on the date of the interview; one remained in the possession of the researcher and the other of the participant. In cases where the interview was conducted digitally (at the participant's choice), two digitally signed copies of the FICF were sent by email, and a copy, after the participant's signature, was returned by email to the researchers for archiving.

The interviews were conducted respecting the choice of the participants. Thus, 11 interviews were performed in person, in a private place, four of which were conducted on the University premises and seven in a hospital environment. Six interviews were conducted through Skype digital media, as the nurses lived in different cities from the researchers. All were recorded using digital mechanisms (mobile recorder program installed on a Smartphone) with the consent of the interviewees, for later transcription and data analysis. This process was carefully explained to the participants, ensuring the preservation of anonymity and ownership of the files exclusively by the researcher. The interviews lasted an average of 40 minutes each.

Study participants had their identities preserved and were identified by the vowel"E", followed by a number, respecting the order in which the interviews were conducted. Thus, they were identified as: E1, E2, E3, E4, E5, E6, E7, E8, E9, E10, E11, E12, E13, E14, E15, E16 and E17. 
Data were collected during the interviews, with the help of two instruments: one of sociodemographic characterization and professional history, which contained information about age, time since graduation, type of institution where worked, if had any specialization, time working in the Neonatal ICU and religion, and a semi-structured interview, based on the following guiding question: "Tell me about your experience in the process of communicating bad news to the family of the newborn in palliative care". Other questions arose during the interviews to achieve the proposed objective:"What do you mean by communication of bad news?", "Tell me one situation in which you experienced a situation of communicating bad news to the newborn's family in palliative care", "What were the consequences of this experience for you?", "How do you believe you can help the family in this the face of this?", "What needs do you identify in this process? Can you answer them?".

The interviews were conducted by three of the researchers, one of whom has a specialization in palliative care and was responsible for the previous orientation and training of the other researchers to conduct the subsequent interviews.

For the treatment and analysis of the data collected through the semi-structured interview script, it was used the framework of content analysis proposed by Bardin ${ }^{(14)}$, following the three fundamental phases proposed: phase I: pre-analysis (Work organization phase. It involves the first contact with the data, that is, the preparation for the analysis that will guide the interpretation of the data; in this phase, there is the transcription of the interviews); phase II: exploration of the material (choice of the coding units, adopting the procedures of coding, classification and categorization of the data, to support the classification into blocks that express certain categories); and phase III: data processing: inference and interpretation (phase in which the data become significant and valid; the latent content arouses interest in the researcher, since the meaning is behind what was immediately apprehended, triggering the interpretation of the assigned meanings).

In summary, the analysis of the interviews was conducted in a coding process, in which the interviewee's speech was "translated" so that his intention and meanings when describing and telling certain situations became clearer. Afterwards, the codes were separated into categorization. At the end of the analysis, the categories constituted the synthesis of the studied experience $\mathrm{e}^{(15)}$.

As for the analysis of data regarding the completion of the questionnaire to identify the research subjects, they were tabulated in the Microsoft Excel ${ }^{\circledR}$ software and will be presented in a descriptive way. It is noteworthy that no software was used for qualitative analysis of the obtained data.
It is noteworthy that the study complied with the ethical precepts recommended by resolution no. 466/2012 of the National Health Council of the Ministry of Health and data collection was only started after approval by the Research Ethics Committee of the School of Nursing of the Universidade de São Paulo, CAAE process: 49860315.4.0000.5392, opinion no. 1.433.734.

\section{RESULTS}

Regarding the characterization of the participants, it is noteworthy that all were women, aged between 24 to 49 years. The training time ranged from one to 26 years; all had a specialization in neonatology. The specific performance in the neonatal ICU ranged from one to 16 years. It is noteworthy that eight participants worked in private institutions and the others in public institutions. It is also noteworthy that six participants were Catholic, four were Spiritists, five were Evangelicals and two declared that they did not follow a specific religion.

Subsequently to the coding and analysis of the data, four thematic categories emerged, with 11 subcategories inserted, compiling the experience of nurses with newborns in palliative care and the process of communicating bad news. The categories will be explained below.

\section{1) Meanings attributed to bad news.}

To mean the bad news refers to nurses' perceptions about the concept. The way the bad news is understood is generally associated with subjectivities and repertoires of professional experiences based on daily practice. Bad news encompasses the way it is understood, the axes that permeate it and the act of communication, described in the following subcategories:

\section{Representing the bad news: "Worst moment we live."}

I understand that it's the worst moment we live [...] we already live in the bad situation of a child getting worse or dying and when we have to call the parents [...] then like this, it seems that the time to break the news is even worse than losing the child. (E3)

I think it's one of the worst phases here, it's the part that I'm particularly afraid of, because I don't know how to deal with it much, because we're never prepared to deal with it... (E11) 


\section{Dealing with expectations and plans: "We undo these dreams."}

Parents make plans for their children, right? I know, I did it for mine, we plan, think about everything that could be [...] here we undo these dreams when we give bad news, I think that defines it, you know, go there, give bad news about the child's prognosis, and ends up with all that family's plans [...] it is very painful! (E17)

Dealing with the eminence of death: "The family still believes in a miracle."

[...] Or is at the time to include this baby in palliative care; that sometimes the family do not accept it at all, the baby is all malformed, full of neurological sequelae, but the family still believes in a miracle. (E17)

\section{Communicating the bad news: "We don't take much further."}

And the communication, usually who does it is the doctor, right? A very serious thing. If it's just a worsening of the condition, we can talk, but usually only he does it. (E6)

This part of going over the clinical picture if it's unstable, stable, in her case, we don't take much further. We always leave it to the doctor because parents sometimes have a lot of questions. Certain things we shouldn't say right? So, this is more medical conduct. (E12)

The reports show the negativity that permeates the communication of bad news, involving not only the act of communicating, but also the subsequent moment. Thus, providing support and embrace to the family is essential, as will be described in the following category.

\section{2) Nursing as a support for the family:}

Nurses recognize that they have a fundamental role, especially in the moment after the communication of bad news. Because the professional is fully involved and because he/she stays most of the time in contact with the patient and family, the presence of the nurse is essential, and his performance takes place in several ways:

\section{Allowing bonding: "Let them be real parents."}

So, the concept of maternity, paternity ends up changing and you as a professional, I as a professional had to adapt to their reality, do you understand? So letting them be real parents was what made sense to me, much more than the procedure / used to do with the children, because it is... even if they had no prognosis or therapeutic possibility, you ended up investing in the child, until you knew that the child was really dying that there was nothing else for you to do... (E2)

\section{Understanding the care to the family and their needs: "A word of affection."}

Because, sometimes, they feel so alone here, that then I think they end up having the nursing team that is closer, right? As a support. Because the doctor comes in, talks, examines, and leaves. And nursing is always closer to the patient, right? So, I think this is it. When you're there, give a hug, give support. (E8)

And like, my role there as a nurse is to talk to the mother and see what she understood and clarify what was not clear [...] and really supportive, trying to arrange it in the middle of the bed, making room with 12 children, she can get her baby to understand all this, cry, without 30 people looking at her face and not even talking, don't be like this, don't be like this, don't be like that. Crying bothers a lot of people, but I think it's more of a clarification. (E9) So, I think that a word of affection with the family is worth more than a lot of action, there is nothing to do. (E15) They come to us later with several doubts, several questions, crying a lot, and who really gives this support, this emotional embrace and slowly tries to make people understand the situation is the nursing team that lives together on a daily basis. (E3)

Thus, the reports show that the role of the nurse goes far beyond just being present during the moment of communicating bad news. Their role is to be supportive and be by the family's side, recognizing their needs and thinking of strategies to minimize suffering and anxiety after communication. However, there are several difficulties reported that interfere with the comprehensive role of nurses, such as those described below. 


\section{3) Difficulties in dealing with the process of communicating bad news:}

The process of communicating bad news covers the barriers that emerge during the care of newborns in palliative care and their families, which can hinder the construction of bonds and, consequently, limit the role of nursing in the care process. Rules and demands are raised as barriers that hinder care relationships.

\section{Simplifying the rules: "Allowing the visit to a little brother."}

Maybe allowing the visit to a little brother who didn't know the child, couldn't go to the visit, wow, I've done that many times, like, because you can't, it's hospital rules not to allow children under 12, so it can't, the doctor[...] no, you can't, then you say: oh okay, then the doctor turns his back and we say: come quickly, the child comes in, sees the brother. (E2)

\section{Facing barriers and demands: "We need to customize care."}

And it was really difficult to take care of in that sense, right? To make sense to the family. Because you end up having several routines, several rules, several visiting protocols, actions that you as an institution, you end up preventing those parents from being parents and from becoming parents and this ends up being very complicated to deal with. (E3)

The dynamics of the ICU is very frenetic, right? It doesn't stop, you're always doing something and that ends up leaving some people, some colleagues, someteam members a little unaware of this importance, so yes, it got in the way a lot, because more than rules and routines, there are people in front of us that we need to customize care [...] (E5)

You know, there were so many rules that the family was getting angry with us, I think we ended up pushing the family away from us, you know [...] one day the mother told me that she felt judged by the team and didn't want to talk because we couldn't understand what she was feeling, we couldn't help her to face [...] wow, I felt terrible. (E15)

\section{Facing physical barriers: "Here there is no adequate physical structure."}

\begin{abstract}
Here there is no adequate physical structure. News is given at the bedside when it is a serious condition, or if it is a death, it is often reported in the corridor. It would be nice if it had its own room to share this kind of news, to talk better, together with the psychologist. It doesn't always happen. (E4)
\end{abstract}

Thus, the reports show the numerous barriers that hinder the individualized and humanized action of nurses in terms of care extended to the family. Dealing with such difficulties generates negative impacts on both parties involved. Thus, nurses inevitably get involved with the suffering of the family and seek alternatives to deal with it, as described below.

\section{4) Nursing and involvement with the suffering of the family:}

Involvement with parents of newborns hospitalized in the Neonatal ICU with reserved prognosis is often associated with frequent bad news transmissions. The lack of professional training to deal with these cases, associated with the impossibility of the theme in the training processes and the issue of the Western culture of not talking about death, provide few spaces for the practice of palliative care, triggering the professional's withdrawal as a way of self-protection.

\section{Expressing feelings: "You can't be just a professional."}

You have a lot of feeling involved, because you think: whoever has a child takes care as if they were taking care of the child, whoever doesn't have a child is there because they like it a lot and get involved a lot with it and us [...] (E1)

As for this type of subject, you can't be just a professional and not feel pain and not want to console a mother, because we put ourselves in place a lot. There are months of hospitalization, so we feel a bit like the mother of all of them and when there is a pain like this, a suffering, we also put ourselves in her shoes and so, as much as we try to separate, I know the limit, we suffer. Of course, in a more contained way, but it's still something that hurts there's no way, it's a life is a loss. (E12) 


\section{Having difficulty dealing with the situation: "I don't know how to deal."}

I already arrived at the shift praying when I had a very serious baby, l asked it not to die on my shift, so I wouldn't have to talk to the family, I wouldn't need to witness the farewell scene, it seemed that with that I would suffer less, you know. (E17)

I end up moving away [...] I think I actually hide with the excuse of papers, I don't know how to deal with the situation of having a devastated person because he/she heard that the child has a serious disease, was born with a problem, you know, I I get lost, without action, I think we have no training for this [...] I feel bad for not being able to handle it and I've already gotten sick too, because we get too attached to the children, to the parents, that's it very complicated. (E17)

And that day was a day that moved me a lot because, this mother, she wanted this child so much and she never thought that she would lose this child, especially after it was born. So she sat there in isolation, in the chair and with the child on her lap, and she asked him to come back to her, for him to not go away like that [...] that day there wasn't one here that didn't go off on a tangent, you know, because it moved a lot, right. (E3)

There are numerous factors that affect the way nurses get involved with the family. As reported by professionals, the approximation and creation of a bond with the family and the newborn becomes inevitable and getting involved with suffering is also seen as a consequence of the bond. Some nurses deal less traumatically with the negative situations that permeate care; others choose to walk away because they don't know how to face with them.

\section{DISCUSSION}

The philosophy of palliative care is supported by fundamental pillars and necessary for the provision of care to be of quality. This includes compassion, commitment to care, integrity, respect, shared decision-making between family and team, and communication. The assistance offered to newborns with a reserved prognosis requires specialized care, especially regarding the communication process, a very delicate issue for those involved ${ }^{(16,17)}$.

Within the scope of the Neonatal ICU, nurses classify the communication of bad news as a complicated and exhausting function, which permeates several negative points ${ }^{(17)}$.
For the nurses in this study, giving bad news is witnessing the suffering of the family and needing to deal with the frustration of plans that had been drawn up for that child's life. In addition, the process involves, in most cases, needing to say that the child is dying or has died, causing great wear on the team as well. Nurses understand that communicating bad news is an arduous process, which generates negative impacts on those who receive it and on those who transmit it. These impacts go beyond the communication itself; doubts and fears permeate the reaction after bad news, demanding from the nurse professional strategies for readjustment and individualization of care.

Given the range of changes that occur in the lives of parents when their baby is in a neonatal ICU, the existence of horizontal dialogical relationships between professionals and the family is essential, favoring the continuity and extension of care for the child, with explanations that clarify the situation, also enabling shared decision-making between the parties involved. Thus, it is noteworthy that an adequate multidisciplinary relationship and the establishment of dialogue could benefit communication with the parents of newborns in palliative care, including information about the environment, routines, devices and procedures, in addition to valuing shared decisions ${ }^{(15)}$.

Regarding the role of nurses in this context, there is a shortage of studies that point to their participation in the act of communicating bad news. This fact is justified by the absence of contents that address the process during the undergraduate course or training on the subject, lack of skills and encouragement, and for not having permission from other professionals to perform it ${ }^{(4)}$.

The findings of this study corroborate the literature: professionals understand that the physician is the appropriate figure to transmit the bad news, something widely reported in the interviews conducted. It is evident that a hierarchical professional relationship is established, without spaces for joint dialogue for decision-making, since several communication barriers between the medical team and the nursing team are rooted in the services ${ }^{(3,5,6)}$.

The International Code of Ethics for Nurses points out that the role of nursing in the process of communicating bad news is to offer care to the patient and family. Thus, ensuring the family stays with the baby, encouraging physical contact, ensuring the privacy of family members in the event of death, clarifying doubts, and answering the needs are some strategies that the literature points out that can and should be adopted by professionals involved in the care in order to make it horizontal and humanized, data that corroborate the findings of the study. The professional seeks 
to readjust and make flexible a range of factors in order to make the situation more welcoming and less traumatic for the family member ${ }^{(15)}$.

In light of the literature, it is seen that in many neonatal intensive care units, the recognition of the family, especially in the context of a difficult prognosis and imminent chance of death, is something that is strongly discussed and encouraged, as mentioned in the reports. The objective of palliative care in neonatology is to relieve the pain and suffering of the newborn and, at the same time, ensure that the needs of parents are met ${ }^{(6)}$.

Parents must be involved in decisions about how, when, and where support for prolonging life will be withdrawn, as well as having their wishes met. Empathy emerges beyond welcoming at the first visit: it needs to be present in all aspects of patient and family care, individualizing the needs elucidated ${ }^{(18)}$.

It is evident the nursing professional's concern in offering constant support, providing comfort and support during this time, since the environment of an ICU is stressful. The care offered is essential to ensure a less traumatic stay for parents in the sector. Furthermore, the relationship between the team and the family is fundamental for the gradual preparation of parents for the occurrence of a possible baby's death, providing a well-established bond and minimizing complicated mourning, revalidating the findings of this study $(6,19)$.

There are reports in this study that show the nurse's distancing due to the inability to answer the questions raised by parents. Professionals are not always willing to welcome the family as expected, and not all families are willing to create bonds and expose their needs. Often, they do not feel comfortable exposing their doubts and anxieties and often resort to silence and crying ${ }^{(4)}$. Also, the reports show that some professionals did not feel emotionally prepared to participate in the process of communicating bad news, while others felt sensitized to the situation, needing to intervene in order to humanize the post-communication process.

Although the importance of including the family in the ICU is undeniable, the nurse also comes up against the operating conducts governed by administrative rules, in order to ensure the proper functioning of the unit. Although in some units there is flexibility in the visiting hours of parents due to a range of factors that prevent them from going to the ICU at the established times, there are still many barriers that negatively affect this issue, especially at night, which hinders the humanization of the care ${ }^{(8)}$.

The continuous experience of nurses in the Neonatal ICU is not enough to prepare them to deal with the bad news involving a newborn, as it elucidates feelings of guilt, failure and impotence in the face of the case $\mathrm{e}^{(16)}$. Faced with these situations, even if they are not prepared, professionals try to show their importance and help the family, guaranteeing their privacy, making themselves available to them, a fact that also permeated the research results.

It must not fail to mention that the process of communicating bad news is a complex activity that requires knowledge, expertise, and skill. The educational process in this direction is essential for health professionals to develop and refine their communication techniques and skills to communicate a bad news. Clinical simulation appears as one of the possible techniques for learning this skill. However, isolated techniques and training, as well as knowledge learned at specific moments during graduation would not be enough to guarantee the effectiveness of learning. The literature points out that it would be essential for these skills to be taught and learned through a continuous process ${ }^{(20)}$.

In addition, the implementation of palliative care in the context of Neonatal Intensive Care Units (ICU) is still little discussed and stigmatized. A study conducted with the objective of knowing the experiences of nursing care practices in relation to the care offered to newborns and their families in the end of life situation in a Neonatal ICU, showed that there is a lack of interprofessional discussion about the practices, lack of implementation of a care plan for babies in critical prognoses incompatible with life and lack of communication involving decision-making, which are centered on the medical team, thus making the participation of other team professionals in the process scarce ${ }^{(6)}$.

\section{FINAL CONSIDERATIONS}

The experiences of nurses working in the Neonatal ICU in situations involving a newborn in palliative care and the process of communicating bad news are complex and arduous. This process is seen as unpleasant, permeated with negative consequences for both parties: family and professional involved. Some associated the bad news with the baby's death and others associated it with any negative fact that the family would not expect. Professionals see this moment as the breaking of dreams and expectations, classifying it as negative and painful. Although nurses do not actively act in the communication of bad news, their role is recognized as fundamental in the moment after the communication, mainly providing support, clarifying doubts, meeting needs and individualizing care for the patient and family.

The study showed that there are many barriers that prevent efficient and humanized care, such as, for example institutional rules, pre-stablished routines, physical barriers such as lack of adequate infrastructure, in addition to the individuals involved in the care themselves, since they are 
not all interested in the flexibility and readjustment of care. Therefore, the professional tries to propose strategies to adapt the reality of the service to the needs of parents.

It is pointed out as a limitation of the study, the absence of nurses who worked in institutions with established neonatal palliative care services that could help in understanding the process of communicating difficult news in these environments. Thus, it is recommended the relevance of conducting other studies that aim to explore possible differences between this context of care regarding the role of nursing in the process of communicating bad news.

This research shows the need to promote spaces for reflection on the care offered to newborns in palliative care and their families during the process of communicating bad news. In addition, it is evident the strong participation of nurses, as well as their fundamental and indispensable participation in the process of communicating bad news, in the reception and interventions with these families, which also aim to prevent complicated mourning when the disease progresses, or the death of the child is inevitable.

\section{REFERENCES}

1. Marc-Aurele KL, English NK. Primary palliative care in neonatal intensive care. Semin Perinatol. 2017:41(2):133-9.doi: https://doi.org/10.1053/j.semperi.2016.11.005.

2. Silva EMB, Silva MJM, Silva DM. Perception of health professionals about neonatal palliative care. Rev Bras Enferm. 2019;72(6):1707-14. doi: https://doi. org/10.1590/0034-7167-2018-0842.

3. World Health Organization. Integrating palliative care and symptom refief into paediatrics: a WHO guide for health care planners, implementers and managers. [internet]. Gevena: WHO; 2018 [cited 2021 May 21]. Available from: https:// apps.who.int/iris/bitstream/handle/10665/274561/9789241514453-eng. pdf? sequence $=1 \&$ isAllowed $=y$.

4. Parravicini E. Neonatal palliative care. Curr Opin Pediatr. 2017;29(2):135-40. doi: https://doi.org/10.1097/mop.0000000000000464.

5. Fontes CMB, Menezes DV, Borgato MH, Luiz MR. Communicating bad news: an integrative review of the nursing literature. Rev Bras Enferm. 2017;70(5):1089-95. doi: http://doi.org/10.1590/0034-7167-2016-0143.

6. Prado RT, Leite IL, Castro EAB, Silva LJ, Silva IR. Uncovering care for patients in the death/dying process and their families. Rev Gaúcha Enferm. 2018;39:e2017-0011. doi: https://doi.org/10.1590/1983-1447.2018.2017-0111.
7. Warnock C, Buchanan J, Tod AM. The difficulties experienced by nurses and healthcare staff involved in the process of breaking bad news. J Adv Nurs. 2017;73(7):1632-45. doi: https://doi.org/10.1111/jan.13252.

8. Almeida FA, Moraes MS, Cunha MLC. Taking care of the newborn dying and their families: nurses' experiences of neonatal intensive care. Rev Esc Enferm USP. 2016;50 (n.esp):122-9. doi: https://doi.org/10.1590/ S0080-623420160000300018.

9. Marçola L, Zoboli I, Polastrini RTV, Barbosa SMM. Breaking bad news in a neonatal intensive care: the parent's evaluation. Rev Paul Ped. 2020;38:e2019092. doi: https://doi.org/10.1590/1984-0462/2020/38/2019092.

10. Silva IN, Salim NR, Szylit R, Sampaio PSS, Ichikawa CRF, Santos MR. Knowing nursing team care practices in relation to newborns in end-oflife situations. Esc Anna Nery. 2017;21(4):e20160369. doi: http://doi. org/10.1590/2177-9465-ean-2016-0369.

11. Minayo MCS, Deslandes SF, Gomes RC. Pesquisa Social: teoria, método e criatividade. 28. ed. Petrópolis: Vozes. 2009.

12. Biernacki $P$, Waldorf D. Snowball sampling: problems and techniques of chain referral sampling. Sociol Methods Res. 1981;10(2):141-63. doi: https://doi. org/10.1177/004912418101000205.

13. Sandelowski M. The problem of rigor in qualitative research. ANS Adv Nurs Sci. 1986;8(3):27-37. doi: https://doi.org/10.1097/00012272-198604000-00005.

14. Bardin L. Análise de conteúdo. Lisboa: Edições 70; 2006.

15. Sieg SE, Bradshaw WT, Blake $S$. The best interests of infants and families during palliative care at the end of life: a review of the literature. Adv Neonatal Care. 2019;19(2):e9-e14. doi: https://doi.org/10.1097/ANC.0000000000000567.

16. Kain VJ, Chin SD. Conceptually redefining neonatal palliative care. Adv Neonatal Care. 2020;20(3):187-95. doi: https://doi.org/10.1097/ ANC.0000000000000731.

17. Hammond J, Wool C, Parravicini E. Assessment of healthcare professionals' self-perceived competence in perinatal/neonatal palliative care after a 3-day training course. Front Pediatr. 2020;8:571335. doi: https://doi.org/10.3389/ fped.2020.571335.

18. Mufato LF, Gaiva MAM. Reasons why of nurses empaty with newborn families in neonatal ICU. Rev Gaúcha Enferm. 2020;41:e20190508. doi: https://doi. org/10.1590/1983-1447.2020.20190508.

19. Silva ACL, Santos GN, Aoyama EA. A importância da assistência de enfermagem na unidade de terapia intensiva neonatal. ReBIS. 2020 [citet 2021 May 21];2(1):4954. Available from: https://revistarebis.rebis.com.br/index.php/rebis/article/ view/69/63.

20. Ghoneim N, Dariya V, Guffey D, Minard CG, Frugé E, Harris LL, et al. Teaching NICU fellows how to relay difficult news using a simulation-based curriculum: does comfort lead to competence?Teach Learn Med. 2019;31(2):207-21. doi: https:// doi.org/10.1080/10401334.2018.1490649. 


\section{- Acknowledgments:}

FAPESP - Fundação de Amparo à Pesquisa do Estado de São Paulo by the scientific Initiation Scholarship granted (Process no. 2017/04152-0).

\section{- Authorship contribution:}

Conceptualization - Beatriz Helena Naddaf Camilo. Data curation - Beatriz Helena Naddaf Camilo, Álida Maria de Oliveira Andreato, Júlia Rudzinski Roveri, Maira Deguer Misko.

Formal analysis - Beatriz Helena Naddaf Camilo, Natália Rejane Salim, Maira Deguer Misko.

Investigation - Beatriz Helena Naddaf Camilo, Maira Deguer Misko.

Methodology - Beatriz Helena Naddaf Camilo, Maira Deguer Misko.

Writing-original draft - Beatriz Helena Naddaf Camilo, Taynnara Caroline Serafim. Writing-review \& editing - Beatriz Helena Naddaf Camilo, Taynnara Caroline Serafim, Natália Rejane Salim, Maira Deguer Misko.

Validation - Maira Deguer Misko.

Visualization - Maira Deguer Misko.

Supervision - Natália Rejane Salim.

The authors declare that there is no conflict of interest.

\section{- Corresponding author:}

Beatriz Helena Naddaf Camilo

E-mail: beatriz.h.camilo@hotmail.com

Associate editor:

Wiliam Wegner

Approved: 07.09.2021

Editor-in-chief:

Maria da Graça Oliveira Crossetti 